\title{
Evaluation of Habitat Characteristics and the Appropriate Scale for Evaluating Diurnal Habitat Selection of Wintering American Woodcock in Louisiana
}

\author{
ELISA C. ELIZONDO, ${ }^{1}$ School of Renewable Natural Resources, Louisiana State University, Baton Rouge LA 70803 \\ JEFFREY P. DUGUAY, Louisiana Department of Wildlife and Fisheries, Baton Rouge, Louisiana 70898 \\ BRET A. COLLIER, School of Renewable Natural Resources, Louisiana State University Agricultural Center, Baton \\ Rouge LA 70803
}

\begin{abstract}
Migratory bird species pose serious management challenges because it is difficult to determine habitats utilized during their entire life cycles. As American woodcock populations have experienced long-term declines, wintering habitat management has become increasingly important. Past studies on woodcock have relied predominantly on Very High Frequency (VHF) telemetry, which require an observer to manually track them to gather location information. Our study employed both Global Positioning System (GPS) and VHF tags on woodcock to gather high resolution movement data in order to evaluate habitat use and compare VHF and GPS approaches to habitat sampling. We simulated a VHF approach to tracking the same individuals from the GPS tag data (spanning 252 bird-days) and utilized vegetation samples from our VHF tracked birds to evaluate use and random paired location sampling. We found that many random locations fell within the Minimum Convex Polygons (MCP) as defined via the GPS tags (average diurnal MCP size was o.04 ha). Overall, our results suggest that evaluating resource selection by woodcock requires discerning the appropriate scale(s) of habitat selection via the identification of the spatial and temporal components underlying individual movement ecology.
\end{abstract}

Proceedings of the American Woodcock Symposium 11: 124-129

KEY WORDS: American woodcock, habitat use, radio telemetry, spatial ecology, vegetation sampling

In managing for a particular wildlife species it is vital to consider its full annual life cycle, as selective pressures driving demography and population dynamics are often differentially influenced at various life cycle stages. This is particularly true with migratory bird species because demography varies significantly between time spent on the breeding grounds, during migration, and on the wintering grounds (Sillett and Holmes 2002, Rotics et al. 2017). While survival on breeding habitat is important for migratory bird populations (Peron et al. 2012), the impact of habitat quality during migration and winter is not as clearly defined. However, wintering habitat can impact success across the full annual cycle (Marra and Holmes 2001, Rushing et al. 2016, Ruiz-Sanchez et al. 2017).
The American Woodcock (Scolopax minor; hereafter woodcock) is a migratory game bird that breeds primarily in the northern midwestern and northeastern states of the United States and southeastern Canada and winters in the southeastern United States. Woodcock are managed by the United Stated Fish and Wildlife Service (USFWS) and the Canadian Wildlife Service (CWS) as two distinct populations, the Central and Eastern populations (Seamans and Rau 2017). The Central population is thought to migrate generally along the Mississippi River corridor while the Eastern population follows the Atlantic coast, although crossover between populations occurs regularly (Moore and Krementz 2017). Both populations of woodcock utilize primarily early successional forests with dense under-

1 email: eelizo2@lsu.edu 
growth throughout their breeding range (Straw et al. 1994, Dessecker and McAuley 2001, McAuley et al. 2005), but use a wide variety of upland and bottomland hardwoods, mixed pine-hardwoods, and managed pine forests on the wintering grounds as long as understory vegetation is adequate (Dyer 1976, Krementz and Pendleton 1994, Straw et al. 1994). Population monitoring data indicate declines in both regions (Seamans and Rau 2017), and these declines have been attributed primarily to the loss of early successional habitat on breeding grounds (Dessecker and McAuley 2001).

As woodcock populations have declined, focus on wintering habitat management has become increasingly important, particularly in the Lower Mississippi Alluvial Valley (LMAV), where adult female survival rates may be particularly low (Pace 2000). Furthering our understanding of how woodcock select and use habitats during the wintering period has also been identified as a priority information need for woodcock by the Association of Fish and Wildlife Agencies Migratory Shore and Upland Game Bird support task force (Case and Associates 2010). Usable habitat types must occur regularly within some larger landscape because woodcock are thought to travel relatively short distances between diurnal and nocturnal sites (Berdeen and Krementz 1998, Masse et al. 2013)

Past studies on woodcock have relied predominantly on Very High Frequency (VHF) telemetry that required an observer to manually approach woodcock to determine location (Hudgins et al. 1985, McCauley et al. 1993, Krementz and Pendleton 1994). Paired sampling, wherein habitat data are collected at the located position as well as at a random location, is typically used to distinguish between use and available areas (Dyer 1976) in avian studies employing VHF telemetry. Vegetative conditions at use areas can then be compared to overall available vegetative conditions to determine if particular resources are used in proportion to their availability (Manly et al 2002).

The advent of Global Positioning System (GPS) tag technology facilitates the assessment of common vegetation sampling techniques. Woodcock habitat evaluations typically occur at the scale of the stand (Myatt and Krementz 2007) or in relation to where individuals are flushed (Dyer 1976). However, without knowledge of the daily use area of woodcock, our concern is that that without a well-defined daily utilization distribution, random locations (availability component; Manly et al. 2002) could potentially fall in the use region, leading researchers to unknowingly compare use locations to use locations. GPS tags have the ability to collect and store data at programmable intervals, allowing large quantities of high-resolution spatial data to be recorded. We used daily movement GPS data to evaluate the assumption that paired random vegetation points are not used by the woodcock and to provide some direction on refining the appropriate spatial and temporal scale for evaluating woodcock habitat selection.

\section{Study Area}

We conducted our research in the Mississippi Alluvial Valley (MAV) and the West Gulf Coast Plains regions of Louisiana (Figure 1). Focal public lands included the Tensas River National Wildlife Refuge $(32,350 \mathrm{ha})$ and the Dewey Wills (25,859 ha), Sherburne (17,80o ha), Bayou Pierre (895 ha), and Richard K. Yancey (28,250 ha) Wildlife Management Areas (WMAs). We also utilized private land near the towns of Palmetto, Deridder, and Boyce, LA, during this study. Most lands were dominated by bottomland hardwoods (all public tracts and 1 private tract). Upland pine (mostly loblolly pine Pinus taeda) was the predominant habitat type on 2 private tracts. Active forest management, including single tree selection, group selection, and small clearcutting, resulted in forests with a variety of age classes on all public lands, while small clearcutting occurred on the private lands Boyce study site. Open, wet fields (either fallow or harvested row-crops) within close proximity to woodlands were present within each site to varying degrees.

\section{Methods}

\section{WOODCOCK CAPTURE, TAGGING, AND TRACKING}

We captured woodcock in October 2015 - February 2016 and November 2016 - February 2017. We located woodcock at night via spotlighting from all-terrain vehicles in fields and captured them using a dip net $(45 \mathrm{~cm}$

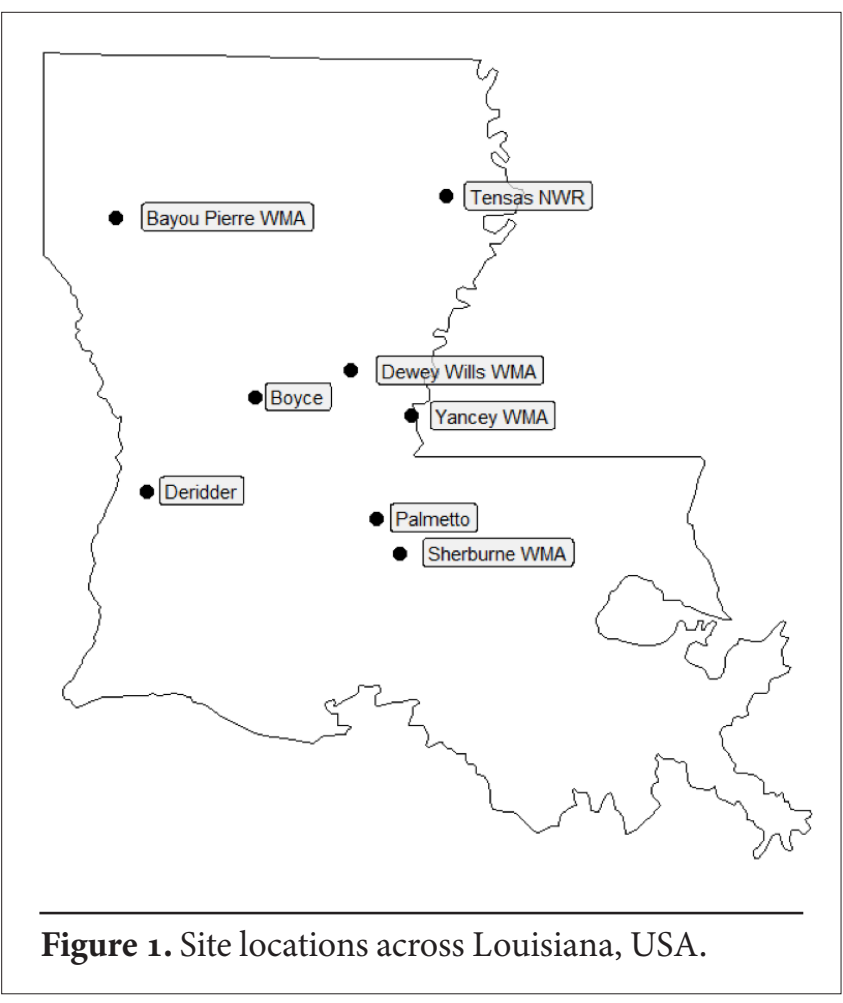


in diameter) attached to a 3-m pole. Upon capture, we banded woodcock with U. S. Geological Survey aluminum bands (BBL Permits 23578 and 06669). We also classified each individual by age and sex.

We utilized VHF and combined GPS-VHF Pinpoint (hereafter Pinpoint) tags on woodcock for our work. VHF transmitters weighed $4.5 \mathrm{~g}$ (Lotek Wireless, Newmarket, Ontario) and were glued to the back of each woodcock using livestock tag cement and then secured with a coated metal belly band and aluminum crimp (McAuley et al. 1993). Pinpoint tags were $5.5 \mathrm{~g}$ and stored GPS locations on-board. We deployed Pinpoint tags using a modified leg-loop attachment (Rappole and Tipton 1991, Mallory and Gilbert 2008) secured with an elastic harness (Stretch Magic Clear Bead Cord, 0.7 mm diameter) and soft PVC tubing (Pony Bead Lacing, $2 \mathrm{~mm}$ diameter) to disperse pressure from the harness. We programmed each Pinpoint tag to take GPS fixes at an interval between 1 to 1.5 hours which, depending on tag battery size, would last between 3 and 18 days. We programmed the VHF component to emit a signal between the hours of 0900 and 2100 after GPS data were collected to assist with recovery. Upon recovery, Pinpoint tags yielded up to 300 spatial locations per deployment.

We radio-tracked VHF-only-tagged woodcock weekly. If an individual was relocated within three days of its capture, we noted its status (i.e., alive or dead) but did not utilize the location in subsequent vegetation sampling. When individuals were located, we homed in, flushed the individual, and recorded their locations. Pinpoint-tagged woodcock were not VHF tracked until after the scheduled GPS fixes were completed and the VHF beacon was enabled. Once the VHF beacon was active, we searched for individuals at night and, if an individual was located, we attempted recapture via spotlighting. When successful, we removed the transmitter and released the woodcock at the capture site. We also recovered Pinpoint-tagged woodcock using a shotgun or air rifle under Louisiana State University IACUC A2015-07, Louisiana Department of Wildlife and Fisheries Scientific Collection Permit 078 and U.S. Fish and Wildlife Service Scientific Collecting Permit $\mathrm{MB} 20705 \mathrm{C}-\mathrm{o}$. Additional units were recovered via Louisiana hunter harvest during the woodcock hunting season in Louisiana.

\section{VEGETATION SAMPLING}

For VHF-tagged woodcock we used the flush location and a random paired point $20 \mathrm{~m}$ away as vegetation sampling locations (Dyer 1976). At each location, we measured the following vegetation characteristics: (1) canopy cover using a concave spherical densiometer, (2) basal area (ha) using a 10-factor basal area prism, (3) vegetative density using a cover board (Nudds 1977), and (4) ground cover using a Daubenmire frame $\left(0.5 \mathrm{~m}^{2}\right)$ constructed from PVC
(Daubenmire 1959). For the Daubenmire frame, we classified ground cover to the nearest $10 \%$ into the following categories: litter, bare ground, herbaceous-grass cover, and woody cover.

We used GPS data to develop daily measures of space used for Pinpoint-tagged individuals by generating Minimum Convex Polygons (MCPs) using R package adehabitatHR (Calenge 2006) separately for each day and night period, beginning the day after the individual was captured, when there were sufficient location data ( $>5$ locations). Next, we buffered each daily MCP by $20 \mathrm{~m}$ and overlaid a $10 \mathrm{~m} \mathrm{x} 10 \mathrm{~m}$ point grid for vegetation sampling (Geospatial Modelling Environment Version o.7.3.0). In support of other project goals, we conducted vegetation sampling at all flush and randomly paired points, all points within the MCP, and every other point within the MCP buffer. Bird-specific MCPs were later modified into aggregated period MCPs for further analyses.

\section{METHOD COMPARISON}

In order to evaluate the efficacy of the paired random vegetation sampling scheme utilized with our VHF-tagged individuals, we simulated the paired use and availability approach using data obtained from Pinpoint tags. For each day a bird was monitored, we randomly selected one diurnal use point to represent daily tracking of a tagged woodcock. We then generated a random available location to simulate a paired point sampling scheme (Dyer 1976, Straw et al. 1986). For 1,00o simulations we generated three random locations for comparison to available locations for each selected daily location using the following distance categories: 10, 20, 30, 45, 60, 75, and $100 \mathrm{~m}$.

Using GPS data from Pinpoint tags, we next evaluated the frequency of randomly selected non-use spatial locations occurring within use areas over time. We suggest it is likely that woodcock moved outside the boundary of a daily MCP because our GPS data were recorded only once per hour. As such, we combined nearby MCPs into aggregated period MCPs (Figure 2). On average, within a daily (080o1600 ) range (excluding movements exceeding $100 \mathrm{~m}$ ), GPStagged woodcock moved $<20 \mathrm{~m} / \mathrm{hr}$; we thus conservatively selected $20 \mathrm{~m}$ as the cutoff defining nearby MCPs. If MCPs from the same bird fell outside of this $20-\mathrm{m}$ range, they were considered separate MCPs rather than being incorporated into a single aggregated period MCP (Figure 2). We then evaluated the frequency of non-use habitat sampling locations that fell into aggregated period MCPs, which defined known use over the study period, and we estimated the proportion of occurrences of randomly located available points within the known use polygons.

\section{Results}

We captured and banded 273 individuals over the course of our study (143 M, 130 F); of these, 65 were tagged with 
VHF transmitters ( $37 \mathrm{M}: 28 \mathrm{~F}$ ) and 63 were tagged with pinpoint transmitters ( $37 \mathrm{M}: 26 \mathrm{~F}$ ). For VHF-tagged individuals which were subsequently relocated $(n=38)$, the habitat was comprised of a mean basal area of 34.61 sq.m/ ha $(\mathrm{SD}=23.49)$, mean canopy cover was $54.55 \%(\mathrm{SD}=$ 25.59 ), and mean vegetation density was $49.56 \%$ (SD = $26.63)$. For the randomly selected paired vegetation points $(n=38)$, the mean basal area was $43.68(\mathrm{SD}=18.07)$, mean canopy cover was $73.04 \%(\mathrm{SD}=14.64)$, and mean vegetation density was $30.53 \%(S D=29.75)$. Mean canopy cover and mean vegetation density at use points were $25 \%$ less $(\mathrm{t}=3.8664, P=0.0002)$ and $62 \%$ greater $(\mathrm{t}=-2.9378, P=$ $0.0044)$, respectively, than at random points. Mean basal area was similar $(\mathrm{t}=1.89, P=0.06)$.

We recovered 33 of the deployed Pinpoint tags and they recorded 3,760 location points spanning 252 bird-days. The number of days an individual was monitored ranged from 1 to 18 (median $=10)$. Average diurnal MCP size was 0.04 ha (range: $<0.01-0.59$ ha; $n=247$ ) and average aggregated MCP size was 0.27 ha (range: $<0.01-3.54$ ha; $n=67$ ). MCP size varied substantially across sites. While no pattern differentiated pine-dominated sites from bottomland hardwood sites, we note the Sherburne WMA site had substantially larger diurnal MCPs on average than the other sites (Table 1). Average daily movement was 94 m (range: $<1 \mathrm{~m}-4707.87 \mathrm{~m}$ ). Tagged woodcock demonstrated moderate fidelity to diurnal use areas, returning to the same aggregated period MCP $33 \%$ of the time. Based on 1,000 simulated pairs of bird-random locations, random paired locations fell within the aggregated period MCP at a rate of $2.5 \%$ at $100 \mathrm{~m}, 4.7 \%$ at $75 \mathrm{~m}, 6.9 \%$ at $60 \mathrm{~m}, 11.8 \%$ at $45 \mathrm{~m}, 21.7 \%$ at $30 \mathrm{~m}, 35.2 \%$ at $20 \mathrm{~m}$, and $50.6 \%$ at $10 \mathrm{~m}$.

\section{Discussion}

Our results indicate that wintering woodcock across Louisiana utilized habitat with lower canopy cover and higher vegetation density than the randomly sampled locations, corroborating previous findings in the state (Dyer 1976). However, based on our simulation results, we found the paired sampling scheme may not allow for differentiation of habitat selection by woodcock since our samples were separated by $20 \mathrm{~m}$. On average, woodcock utilized a daily area of 0.04 ha $\left(20^{\star} 20 \mathrm{~m}\right)$, Consequently, with a paired sample $20 \mathrm{~m}$ away, our random samples would fall into a known woodcock use area over $35 \%$ of the time.

The frequency of available locations which fall within an individual's area of use may bias vegetation and habitat comparisons, as it conflates the sampling process
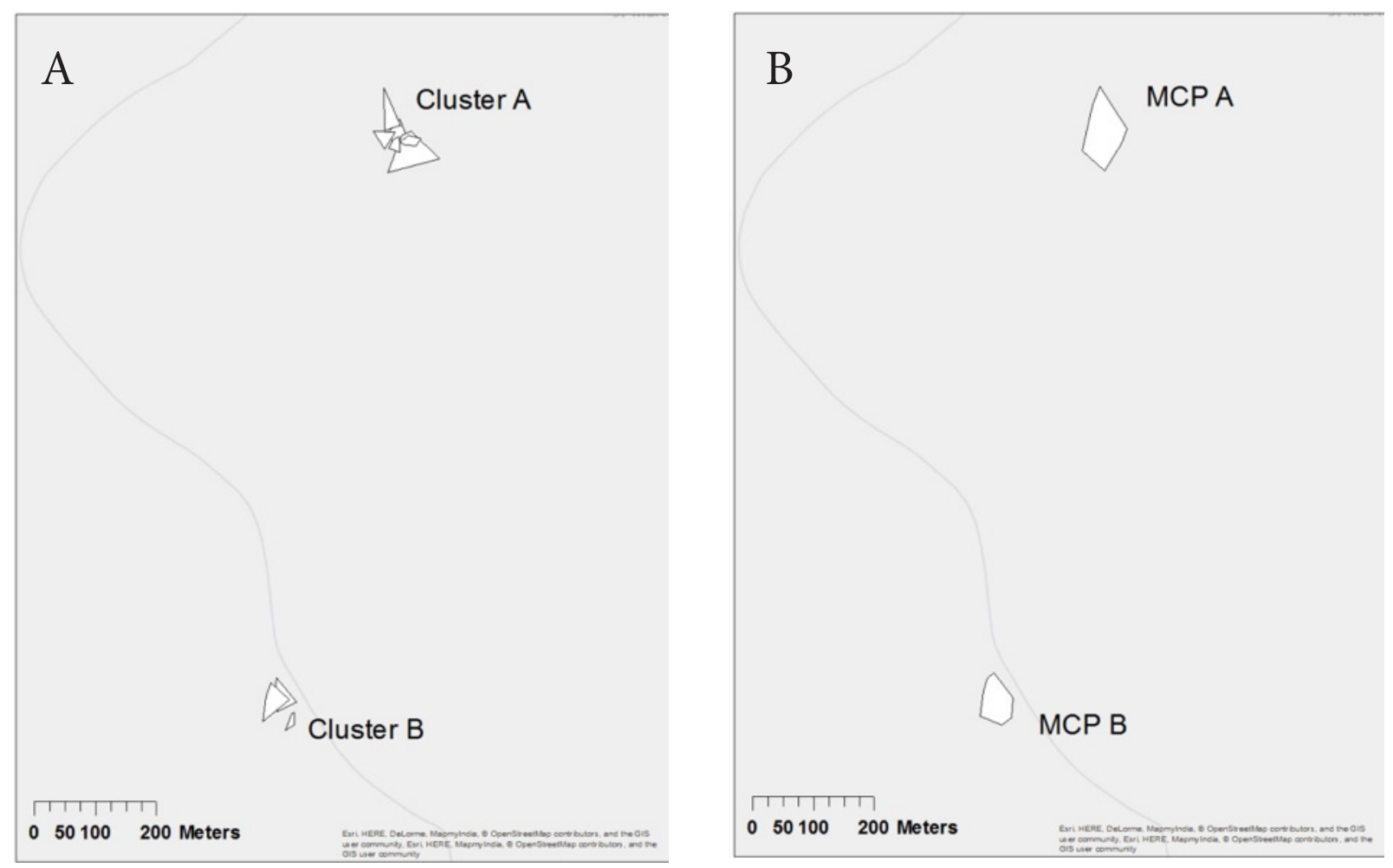

Figure 2. A cluster of MCPs generated for 10 days of one individual (A) and the aggregated daily MCPs generate from the individual MCPs (B). 
underlying the comparison of use to available. Comparing sampling point within the daily or weekly range of a woodcock might be relevant at the micro-habitat level. However, inference at any higher level will risk the comparison of used habitat to more used habitat. Hence, any results indicating selection, either positive or negative, may not be yielding biologically appropriate inferences at the scale at which woodcock habitat management should be conducted. Woodcock represent a unique challenge in regards to evaluating habitat selection. They regularly make large movements across the landscape in the form of nocturnal flights to open fields; once they select a diurnal or nocturnal area, however, movement distances are significantly reduced. Standard definitions of available habitat to an individual should, in theory, include much of the surrounding landscape, as woodcock may utilize habitat within several kilometers of their capture site. However, once in a diurnal or nocturnal use area, woodcock are likely selecting based on microhabitat characteristics such as soil moisture, vegetative cover, or forage availability (Doherty et al. 2010, Masse et al. 2013). Proximity to fields and clearings may also play a large role in the selection of diurnal habitat. While it is well established that woodcock often utilize agricultural fields at night (Blackman et al. 2011, Krementz et al. 2014), woodcock may use a wide variety of other fields and clearings which may be more difficult to quantify on the landscape (Berdeen and Krementz 1998, Masse et al. 2013).

Given these challenges, in situations in which vegetation metrics at paired samples are taken for comparison to habitat for individual woodcocks, we recommend that a minimum buffered radius of $43 \mathrm{~m}$ from the flush location, or an unsampled area covering approximately 0.58 ha (equivalent to our largest diurnal MCP) centered on the flush location, would ensure minimal overlap between

Table 1: Diurnal Minimum Convex Polygon area by site.

\begin{tabular}{|c|c|c|c|}
\hline Site & $\begin{array}{l}\text { Number } \\
\text { of GPS tags } \\
\text { recovered }\end{array}$ & $\begin{array}{c}\text { Broad } \\
\text { Habitat } \\
\text { Classification }\end{array}$ & $\begin{array}{c}\text { Mean } \\
\text { MCP } \\
\text { area (ha) }\end{array}$ \\
\hline $\begin{array}{l}\text { Sherburne } \\
\text { WMA }\end{array}$ & 9 & $\begin{array}{c}\text { Bottomland } \\
\text { Hardwood }\end{array}$ & 0.20 \\
\hline $\begin{array}{l}\text { Richard K. } \\
\text { Yancey WMA }\end{array}$ & 2 & $\begin{array}{c}\text { Bottomland } \\
\text { Hardwood }\end{array}$ & 0.02 \\
\hline $\begin{array}{l}\text { Tensas River } \\
\text { NWR }\end{array}$ & 11 & $\begin{array}{l}\text { Bottomland } \\
\text { Hardwood }\end{array}$ & 0.03 \\
\hline Deridder & 7 & Upland Pine & 0.09 \\
\hline $\begin{array}{l}\text { Bayou Pierre } \\
\text { WMA }\end{array}$ & 1 & $\begin{array}{l}\text { Bottomland } \\
\text { Hardwood }\end{array}$ & 0.02 \\
\hline Boyce & 3 & Upland Pine & 0.03 \\
\hline
\end{tabular}

areas likely used and random locations. However, we note 2 difficulties using this approach: 1) this will not account for inter-individual variation, and 2) the random point for one individual could easily fall directly in the range of other local individuals. MCP overlap was common in woodcock (Elizondo 2018). As distance needed to ensure sample independence between use and random locations increases, the likelihood of transitions between general habitat classes increases as well, thus necessitating a well-defined habitat sampling frame. We also recommend that any inferences drawn from the approach we used are restricted, as they can only reliably predict at small scales-for instance daily woodcock movements within their diurnal use areas. While useful, these inferences will have limited application in a context of landscape management until stronger linkages between woodcock daily and period movements and space utilization are better defined.

As microhabitat characteristics are fairly well established for woodcock, we suggest a focus on larger scale landscape variables in future research. The classification of the landscape may be made within a broadly defined use area established by the movements of many individuals within a particular system (see Masse et al. 2013) or an area that encompasses at least several square kilometers around the areas the woodcock utilize. Woodcock can travel $>2 \mathrm{~km}$ in search of a nocturnal field, both on the breeding grounds (Masse et al. 2013) and on the wintering grounds (Elizondo 2018) and are capable of movements $>4 \mathrm{~km}$ in a single day while settled on the wintering grounds. Thus, all of the habitat within this range is easily available to them, and areas which they fly over when returning to the forests from nocturnal fields are actively selected against. Lastly, we strongly recommend considering the mosaic of forest and potential nocturnal fields in assessing diurnal woodcock habitat use. The quality of nocturnal fields likely plays a largely unexplored role in woodcock diurnal habitat use. This quality may pertain to food availability, likelihood of depredation, or suitability for display. In particular, we recommend making effort to include "non-traditional" clearings that woodcock may use, i.e. smaller areas which may be clearcuts or small forest openings.

\section{Acknowledgments}

Our research was funded by the Louisiana Department of Wildlife and Fisheries. We gratefully acknowledge field assistance from N. Fyffe, S. Madere, N. Bakner, and T. Carlson and the many student workers who assisted in data collection. E. Elizondo gratefully acknowledges the NSF Bridge to the Doctorate Program for supporting her work. This material is based upon work that is supported by the National Institute of Food and Agriculture, U.S. Department of Agriculture, McIntire Stennis project 1005302. 


\section{Literature Cited}

Berdeen, J.B., and D.G. Krementz. 1998. The use of fields at night by wintering American woodcock. Journal of Wildlife Management 62: 939-947.

Blackman, E.B., C.S. Deperno, R.W. Heiniger, M.J. Krachey, and C.E. Moorman, and M.N. Peterson. 2013. Effects of crop field characteristics on nocturnal winter use by American woodcock. Journal of Wildlife Management 76(3): 528-533.

Calenge, C. 2006. The package adehabitat for the R software: a tool for the analysis of space and habitat use by animals. Ecological Modelling, 197: 516-519.

Case, D.J. and Associates. 2010. Priority information needs for American Woodcock: A funding strategy. Developed for the Associated of Fish and Wildlife Agencies by the Migratory Shore and Upland Game Bird Support Task Force. 16pp.

Daubenmire, R.F. 1959. Canopy cover method of vegetation analysis. Northwest Science 33:43-64.

Dessecker, D.R., and D.G. McAuley. 2001. Importance of early successional habitat to ruffed grouse and American Woodcock. Wildlife Society Bulletin 29:456-465.

Doherty, K.E., D.E. Andersen, J. Meunier, E. Oppelt, R.S. Lutz, and J.G. Bruggink. 2010. "Foraging location quality as a predictor of fidelity to a diurnal site for adult female American woodcock Scolopax minor. Wildlife Biology, 16: 379-388.

Dyer, J.M. 1976. An evaluation of diurnal habitat requirements for the American Woodcock in Southern Louisiana. LSU Historical Dissertations and Theses. 2917.

Elizondo, E.C. 2018. Habitat selection, survival, and movement ecology of the American Woodcock (Scolopax minor) in Louisiana, USA.M.S. Thesis, Louisiana State University, Baton Rouge, USA.

Hudgins, J.E., G.R. Storm, and J.S. Wakely. 1985. Local movements and diurnal-habitat selection by male American Woodcock in Pennsylvania. Journal of Wildlife Management 49: 614-619.

Krementz, D. G, R. Crossett, and S.E. Lehnen. 2014. Nocturnal field use by fall migrating American Woodcock in the Delta of Arkansas. Journal of Wildlife Management 78:264-272.

Krementz, D.G., and G.W Pendleton. 1994. Diurnal habitat use of American woodcock wintering along the Atlantic coast. Canadian Journal of Zoology 72: 1945-1950.

Mallory, M.L., and C.D. Gilbert. 2008. Leg-loop harness design for attaching external transmitters to seabirds. Marine Ornithology 36: $183-188$.

Manly, B.F., L. McDonald, D. Thomas, T.L. McDonald and W.P. Erickson. 2002. Resource selection by animals. Springer Netherlands.

Marra, P.P., and R.T. Holmes. 2001. Consequences of dominance-mediated habitat segregation in American Redstarts during the nonbreeding season. The Auk 118: 92-104.

Masse, R.J., B.C. Tefft, J.A. Amador, and S.R. McWilliams. 2013. Why woodcock commute: testing the foraging-benefit and predation-risk hypotheses. Behavioral Ecology 24:1348-1355.

McAuley D.G., J.R. Longcore, D.A. Clugston, R.B. Allen, A. Weik, S. Williamson, J. Dunn, B. Palmer, K. Evans, W. Staats, G.F. Sepik and W. Halteman. 2005. Effects of hunting on survival of American Woodcock in the northeast. Journal of Wildlife Management 69: 1565-1577.

McAuley, D.G., J.R. Longcore, and G.F. Sepik. 1993. Techniques for research into Woodcocks: Experiences and recommendations. Proceedings of the American Woodcock Symposium 8:5-11.

Moore, J. D, and D.G. Krementz. 2017. Migratory connectivity of American Woodcock using band return data. Journal of Wildlife Management, doi: 10.1002/jwmg.21269.

Myatt, N.A. and D.G. Krementz. 2007. Fall Migration and Habitat Use of American Woodcock in the Central United States. Journal of Wildlife Management 71(4): 1197-1205.

Nudds, T.D. 1977. Quantifying the vegetation structure of wildlife cover. Wildlife Society Bulletin 5:113-117.

Pace III, R.M. 200o. Winter survival rates of American Woodcock in south central Louisiana. Journal of Wildlife Management 64: 933-939.

Peron, G., Y. Ferrand, R. Choquet, R. Pradel, F. Gossmann, C. Bastat, M. Guenezan, I. Bauthian, R. Julliard, and O. Gimenez. 2012. Spatial heterogeneity in mortality and its impact on the population dynamics of Eurasian woodcocks. Population Ecology 54:305-312.

Rappole, J.H., and A.R. Tipton. 1991. New harness design for attachment of radio transmitters to small Passerines. Journal of Field Ornithology 62: 335-337.

Rotics, S., S. Turjeman, M. Kaatz, Y.S. Resheff, D. Zurell, N. Sapir, U. Eggers, W. Fiedler, A. Flack, F. Jeltsch, M. Wikelski, and R. Nathan. 2017. Wintering in Europe instead of Africa enhances juvenile survival in a long-distance migrant. Animal Behaviour 126: 79-88.

Ruiz-Sanchez, A., K. Renton, and R. Rueda-Hernandez. 2017. Winter habitat disturbance influences density and territory size of a Neotropical migratory warbler. Journal of Ornithology 158: 63-73.

Rushing, C.S., P.P. Marra, and M.R. Dudash. 2016. Winter habitat quality but not long-distance dispersal influences apparent reproductive success in a migratory bird. Ecology 97:1218-1227.

Seamans, M.E., and R.D. Rau. 2017. American woodcock popuation status, 2017. U.S. Fish and Wildlife Service, Laurel, Maryland, USA.

Sillett, T.S., and R.T. Holmes. 2002. Variation in survivorship of a migratory songbird throughout its annual cycle. Journal of Animal Ecology 71: 296-308.

Straw, J.A., J.S. Wakeley, and J.E. Hudgins. 1986. A model for management of diurnal habitat for American Woodcock in Pennsylvania. Journal of Wildlife Management 50: 378-383.

Straw, J.A., Fr., D.G. Krementz, M.W. Olinde, and G.F. Sepik. 1994. American woodcock. Pages 97-114 in T.C. Tacha and C.E. Braun, editors. Migratory shore and upland game bird management in North America. Revised and updated edition. International Association of Fish and Wildlife Agencies, Washington, D.C., USA. 